\section{Genetic analysis of CRHRA1 and CRHRA2 microsatellites and their association with rheumatoid arthritis in South Asian and Caucasian popula- tions of the East Midlands, UK}

\author{
Anant Ghelani, ${ }^{1,2}$ Sophia Steer, ${ }^{3}$ \\ Sheila A. Fisher, ${ }^{4}$ Bhaneeta Mistry, ${ }^{5}$ \\ Leslie Goh, ${ }^{6}$ Adrian Jones, ${ }^{7}$ \\ Ash Samanta, ${ }^{8}$ Sarabjit S. Mastana ${ }^{1}$ \\ 'School of Sport, Exercise and Health \\ Sciences Loughborough University, \\ Loughborough; ${ }^{2}$ School of Science and \\ Engineering, Teesside University, \\ Middlesbrough; ${ }^{3}$ King's College Hospital, \\ Denmark Hill; ${ }^{4}$ King's College London, \\ London; ${ }^{5}$ North East Thames Regional \\ Molecular Genetics Laboratory, Great \\ Ormond Street Hospital, London; \\ 6Musgrove Park Hospital, Taunton, \\ Somerset; ${ }^{7}$ City Hospital, Nottingham; \\ ${ }^{8}$ Leicester Royal Infirmary, Leicester, UK
}

\section{Abstract}

Two microsatellites from corticotropin releasing hormone (CRH) gene locus (CRHRA1 and CRHRA2) were reported to be associated with rheumatoid arthritis (RA) in Caucasians. This study aims to replicate the association in a South Asian (SA) and Caucasian RA sample from the East Midlands, UK. DNA from 281 South Asians (111 patients, 43 siblings, 127 controls) and 287 Caucasians (116 patients, 64 siblings, 107 controls) were genotyped. The Odds Ratio for carrying at least one copy of the CRHRA ${ }^{*} 10$ risk allele was 1.32 (Confidence Interval, $\mathrm{CI}=0.77-2.28$ ) in Caucasians and 1.55 ( $\mathrm{CI}=0.92-2.63)$ in South Asians, indicative of a trend for association. The risk allele CRHRA2*14 was lower in South Asians compared to Caucasians (5.5-8.6\% vs. 17.7-18.2\%; $\mathrm{P}<0.005)$. Significant linkage disequilibrium was observed between CRHRAl and CRHRA2 in both cohorts. CRHRA1*10 was the frequently transmitted allele in SA patients. A non-significant association was observed with CRHRA1*10 allele in both RA populations.

\section{Introduction}

Rheumatoid arthritis (RA) is a common autoimmune disease in which both environmental and genetic factors seem to play a role in the inception, progression, severity and episodic nature of the disease. Genome-wide and candidate association studies have suggested many genetic susceptibility loci, but HLA-DR, and more recently PTPN22, PADI4 and CTLA4, remain the validated genetic markers for RA.1,2 Panayi reported that RA is multifactorial and may be complicated by non HLA factors such as the neuroendocrine hormone, the corticotropin releasing hormone (CRH). ${ }^{3}$ The hormone is released from hypothalamus under the influence of TNF $\alpha$, IL-1 $\beta$ and IL-6.

Centrally, CRH releases pituitary adrenocorticotropin, which in turn stimulates the adrenal cortex to release cortisol from the adrenal gland. The amount of cortisol released is reduced in RA patients. ${ }^{4}$ Lewis rats, which are susceptible to RA induction, also have low cortisol levels. Locally, the CRH levels are increased in the joints of experimental arthritis (in Lewis rats) and in the synovium and synovial fluid of RA patients.5,6 In situ CRH increases the cycloxygenase-2 derived prostaglandins E2 and E1 locally, thus promoting joint disease progression ${ }^{7}$ and pain perception. ${ }^{8}$

Baerwald et al. (2000) ${ }^{9}$ studied the genetic polymorphisms in the promoter region of the CRH gene among Caucasian (UK) and South African black RA patients and found that haplotype A2B1 was protective against developing RA in UK patients whereas allele A1B1 was positively associated with RA in the black South African RA patients $(\mathrm{OR}=1.78$; $\mathrm{CI}=1.01$ 3.15). Gonzalez-Gay et al. ${ }^{10}$ found that CRH-A2 allele was significantly increased only in the late onset sero-negative RA patients from the Lugo region of Spain.

Fife et al. ${ }^{11}$ investigated short tandem repeat (STR)/microsatellite genetic variation at CRHRA1 (8q12.3) in 295 Caucasian families and found a significant excess of allele sharing in affected members and significant linkage over a $22 \mathrm{cM}$ region between markers D8S285 and D8S530. A further STR located 20 $\mathrm{kb}$ downstream of the CRH structural gene named CRHRA2 also showed strong linkage disequilibrium with CRHRA1.12 Fife and colleagues reported that the haplotype (CHRA1*10 - CRHRA2*14) was associated with RA in 131 simplex Caucasian families. ${ }^{12}$ In a Spanish study (121 simplex RA families and 101 healthy controls) significant linkage disequilibrium between the two loci was observed but there was no association of any alleles or haplotypes with RA. ${ }^{13}$ The haplotype RA1*10 - RA2*14 was found to be under-transmitted in the study (12 observed versus 17.43 expected).

Previous studies have shown interesting genetic variation in Caucasian and other ethnic populations ${ }^{9}$ but no studies have examined CRH microsatellite variation in South Asian RA patients. The increased production of PGE1 due to polymorphic CRH, with subsequent hypersensitisation of the pain nerve endings,
Correspondence: Anant Ghelani, School of Science and Engineering, Teesside University, Middlesbrough, Tees Valley, United Kingdom, TS1 3BA, UK. Tel. +44.1642.322553

E-mail: a.ghelani@tees.ac.uk and

Dr Sarabjit Mastana Human Genomics Lab., School of Sport, Exercise and Health Sciences Loughborough University, Loughborough, LE11 3TU, UK. Tel. +44.01509.223041

E-mail: s.s.mastana@lboro.ac.uk

Key words: Rheumatoid Arthritis, South Asian, Caucasian, CRHRA1 and CRHRA2.

Conflict of interests: the authors report no conflict of interests.

Received for publication:11 August 2011.

Revision received: 19 March 2012.

Accepted for publication: 30 March 2012

This work is licensed under a Creative Commons Attribution NonCommercial 3.0 License (CC BYNC 3.0).

(C) Copyright A. Ghelani et al., 2012

Licensee PAGEPress, Italy

Rheumatology Reports 2012; 4:e5

doi:10.4081/rr.2012.e5

may be associated to the differing pain perception in the two ethnic groups as some studies on South Asians have reported lower pain thresholds in RA. This difference in pain may be readily reflected in the severity of self assessed RA. The aim of this study was to determine if the two STRs (CRHRA1 and CRHRA2) are associated with RA in South Asian and Caucasian populations of the East Midlands.

\section{Materials and Methods}

Subsequent to the approvals by local ethical committees and written consent according to the 1996 Declaration of Helsinki, DNA samples were obtained and genotyped from 111 South Asian Patients, 43 South Asian siblings, 127 South Asian controls, 111 Caucasian Patients , 64 Caucasian siblings and 107 Caucasian control. Genotyping for the two CRH microsatellite markers was performed as described by Fife $e t$ al. ${ }^{12}$ in the presence of fluorescently labelled primers (CRHRA1 - (F) 5'-FAM CCC AGT CCC CAT GAT ATC AG -3', (R) 5'-AAC TTT CCC ACC AGT AAT GCC-3' and CRHRA2 - (F) 5'-HEX CAG TTT CCT TGG GCT TCT ACA G -3', (R) 5'-AAG TCC CTA TCT CCA AAG CAA T-3').

Allele and genotype frequencies were compared between cases and controls using chisquared statistics and odds ratios were calculated by Woolf's method. Family based association analysis was carried out using Sib-TDT14 
which tests for association by comparing marker allele frequencies between affected and unaffected siblings which differ in genotype. Haplotype frequencies and linkage disequilibrium between microsatellites were estimated using EHPLUS program. ${ }^{15}$

A questionnaire was used to assess self perception of severity, pain and quality of life. Patients were asked to score three categories for pain and severity in a simple questionnaire as to how they perceived their pain due to RA Mild, Moderate or Severe. The gradations of the duration of disease, self assessed severity and pain were assessed by two-way association analysis using cross-tab (contingency Table) method on SPSS against the CRH genotypes.

\section{Results}

Both microsatellites analysed at the CRH locus (CRHRA1 and CRHRA2) showed wide genetic variation. At CRHRAl locus, 7 genotypes $(8,10 ; 9,10 ; 9,11 ; 10,10 ; 10,11 ; 11,11$; and 11,12 ) accounted for more than $90 \%$ of the genotypic variation observed in various groupings of patients and controls. Two genotypes $(10,11$ and 11,11$)$ were most frequent in all groups accounting for 30 to $60 \%$ of genotypic distribution. Asian groups showed slightly higher frequency of these genotypes (60-61\%) compared to Caucasians (30-59\%). All the four groups (SA Patients and controls; Caucasian Patients and controls) were in HardyWeinberg equilibrium. Two alleles CRHRA1*10 and CRHRA1 ${ }^{*} 11$ accounted for majority of the genetic variation at this locus (Table 1). The risk allele CRHRA1* 10 was higher in cases than controls in both populations but the differences were statistically not significant $(\mathrm{P}=0.11)$.

At the CRHRA2 locus, 71 different genotypes were detected in various groups, though not all genotypes were observed in all groups. Two genotypes $(12,13$ and 12,14$)$ accounted for 10 to $18 \%$ of the frequency variation. The risk allele CRHRA2*14 frequency was slightly higher in South Asian RA compared to controls ( $8.6 \%$ vs $5.5 \%$ ). The frequency of CRHRA ${ }^{*} 11$ was observed to be significantly higher in South Asian RAs (9.90 \% versus 3.1\%, $\mathrm{P}<0.05)$. CRHRA2* 14 was rare in South Asians (5.5\% versus. $18.2 \%$; $\mathrm{P}=0.005)$. When Bonferroni correction $(\mathrm{P}=0.003)$ for multiple comparisons was applied these differences became nonsignificant.

\section{Association analysis}

CRHRA1 and CRHRA2 genotypes were in Hardy Weinberg equilibrium in cases and controls in both populations. Two alleles (CRHRA1*10 and *11) accounted for approximately $80 \%$ of the genetic variation at CRHRAl
(Table 1). In the South Asian cohort, the previously defined risk allele CRHRA1* 10 occurred at a higher frequency in cases (34.3\%) than controls (26.9\%) although this difference did not reach statistical significance $(\mathrm{P}=0.11)$. The frequency of this allele was also slightly higher in Caucasian cases (26.6\%) compared with controls $(23.5 \%)(\mathrm{P}=0.54)$. In the Asian cohort, the odds ratio associated with presence (at least one copy) of CRHRA1*10 was 1.55 (95\% CI $0.92-2.63)$, compared with an odds ratio of $1.32(95 \%$ CI $0.77-2.28)$ in the Caucasian cohort.

There was no significant difference in the frequency of CRHRA $2 * 14$ between either Caucasian cases (17.7\%) and controls (18.2\%, $\mathrm{P}=0.71$ ), or between South Asian cases (8.6\%) and controls ( $5.5 \%, \mathrm{P}=0.26)$. Interestingly, this allele occurred at significantly lower frequency in the South Asian than Caucasian controls $\left(\mathrm{P}=3.0 \times 10^{-5}\right)$. We did, however, observe a significant increase in the frequency of CRHRA2*11 in South Asian cases (9.9\%) than controls (3.1\%) $(\mathrm{P}=0.0045)$, though after multiple comparison correction, it became no-significant.

\section{Linkage disequilibrium analysis}

Haplotype frequencies were estimated in 218 South Asians (102 RA Patients and 116 Random Controls) and 208 Caucasians (109 RA Patients and 99 Random Controls) using

Table 1. CRHRA1 and CRHRA2 allele frequencies in two rheumatoid arthritis populations.

\begin{tabular}{|c|c|c|c|c|c|c|c|c|}
\hline \multirow{3}{*}{$\begin{array}{l}\text { STR } \\
\text { Group } \\
\text { Allele number }\end{array}$} & \multicolumn{8}{|c|}{ Allele frequencies (\%) } \\
\hline & \multicolumn{2}{|c|}{ South Asian } & \multicolumn{2}{|c|}{ Caucasian } & \multicolumn{2}{|c|}{ South Asian } & \multicolumn{2}{|c|}{ Caucasian } \\
\hline & $\begin{array}{c}\mathrm{RA} \\
(\mathrm{n}=105)\end{array}$ & $\begin{array}{l}\text { Controls } \\
(\mathrm{n}=119)\end{array}$ & $\begin{array}{c}\mathrm{RA} \\
(\mathrm{n}=111)\end{array}$ & $\begin{array}{l}\text { Controls } \\
(\mathrm{n}=100)\end{array}$ & $\begin{array}{c}\mathrm{RA} \\
(\mathrm{n}=111)\end{array}$ & $\begin{array}{l}\text { Controls } \\
(\mathrm{n}=127)\end{array}$ & $\begin{array}{c}\mathrm{RA} \\
(\mathrm{n}=116)\end{array}$ & $\begin{array}{l}\text { Controls } \\
(\mathrm{n}=107)\end{array}$ \\
\hline 3 & & & & & 0 & 0.4 & 0 & 0 \\
\hline 4 & & & & & 4.5 & 6.3 & 1.7 & 2.3 \\
\hline 5 & 0 & 0 & 0.5 & 0 & 0 & 1.6 & 0.9 & 0.5 \\
\hline 6 & & & & & 0 & 0 & 0.4 & 0.9 \\
\hline 7 & 0 & 0 & 0 & 0.5 & & & & \\
\hline 8 & 2.4 & 2.1 & 3.2 & 3.5 & 0 & 0.4 & 0 & 0 \\
\hline 9 & 3.3 & 4.2 & 8.6 & 7.5 & 1.4 & 0 & 0.4 & 1.4 \\
\hline 10 & $34.3^{*}$ & 26.9 & $26.6^{*}$ & 23.5 & 1.4 & 0 & 3.9 & 4.7 \\
\hline 11 & 48.6 & 53.4 & 51.8 & 56 & $9.9^{\circ}$ & 3.1 & 8.6 & 6.5 \\
\hline 12 & 7.6 & 7.1 & 7.7 & 6.5 & 20.3 & 24.4 & 26.3 & 26.2 \\
\hline 13 & 2.4 & 3.8 & 1.4 & 2.5 & 11.3 & 14.2 & 12.1 & 14 \\
\hline 14 & 1 & 0.8 & 0.5 & 0 & $8.6^{\#}$ & 5.5 & 17.7 & 18.2 \\
\hline 15 & 0.5 & 1.7 & 0 & 0 & 15.8 & 12.2 & 6 & 8.9 \\
\hline 16 & & & & & 14 & 15.7 & 16.8 & 11.7 \\
\hline 17 & & & & & 10.8 & 9.1 & 3.9 & 1.9 \\
\hline 18 & & & & & 2.3 & 4.7 & 1.3 & 1.9 \\
\hline 19 & & & & & 0 & 2.4 & 0 & 0.5 \\
\hline 20 & & & & & 0 & 0 & 0 & 0.5 \\
\hline
\end{tabular}


Table 2. CRHRA1 - CRHRA2 haplotypes with $>2.5 \%$ frequency in rheumatoid arthritis and Controls of either ethnicity, estimated with EHPLUS programs.

\begin{tabular}{|c|c|c|c|c|c|}
\hline \multirow{2}{*}{\multicolumn{2}{|c|}{ Haplotype }} & \multicolumn{4}{|c|}{ Haplotype frequency (\%) } \\
\hline & & & & South & \\
\hline $\begin{array}{l}\text { CRHRA1 } \\
\text { Allele }\end{array}$ & $\begin{array}{l}\text { CRHRA2 } \\
\text { Allele }\end{array}$ & $\begin{array}{c}\text { RA } \\
(n=109)\end{array}$ & $\begin{array}{c}\text { Controls } \\
(\mathrm{n}=99)\end{array}$ & $\underset{(n=102)}{R A}$ & $\begin{array}{l}\text { Controls } \\
(\mathrm{n}=116)\end{array}$ \\
\hline 9 & 16 & 2.8 & 1 & 0 & 0 \\
\hline 10 & 11 & 4.4 & 2.5 & 3 & 0.4 \\
\hline 10 & 12 & 1.9 & 2.6 & 3.5 & 2.4 \\
\hline 10 & 13 & 4.4 & 2.6 & 5.2 & 7.4 \\
\hline 10 & 14 & $11.7^{*}$ & $11.1^{\circ}$ & $3 *$ & $2.4^{\circ}$ \\
\hline 10 & 15 & $1.6^{\#}$ & 2.2 & $7^{\#}$ & 2.8 \\
\hline 10 & 16 & $1.2^{\#}$ & 0 & $8.7^{\#}$ & 8.4 \\
\hline 11 & 4 & 0 & 1.5 & 3.4 & 2.9 \\
\hline 11 & 10 & 1.9 & 2.6 & 0 & 0 \\
\hline 11 & 11 & 2.6 & 3.7 & 2 & 0.9 \\
\hline 11 & 12 & 18.7 & 20.7 & 15.9 & 19.9 \\
\hline 11 & 13 & 6.5 & 7.8 & 4.6 & 6 \\
\hline 11 & 14 & 5 & 2.9 & 3.1 & 1.5 \\
\hline 11 & 15 & 2.6 & 5.1 & 4.2 & 7.9 \\
\hline 11 & 16 & 9.6 & 8.4 & 5.4 & 3.9 \\
\hline 11 & 17 & 3.2 & 0 & 8.3 & 4.8 \\
\hline 12 & 16 & 2.5 & 2.3 & 1.1 & 1.9 \\
\hline
\end{tabular}

*Lower frequency in South Asian rheumatoid arthritis; 'lower frequency in South Asian controls; "higher frequency of haplotypes in South Asian cases. Differences were not significant.

EHPLUS. ${ }^{15}$ Significant LD was observed between CRHRA1 and CRHRA2 in both ethnic cohorts (South Asian; $\mathrm{P}=0.0001$ and Caucasian; $\mathrm{P}=0.0084$ ). A total of 17 haplotypes with a frequency of at least $2.5 \%$ accounted for $70 \%$ of all possible haplotypes (Table 2). The previously suggested susceptibility haplotype, CRHRA1*10-CRHRA2* $14,{ }^{12}$ occurred at a lower frequency in Asians compared to Caucasians in both patients (Asian: $3.0 \%$ vs. Caucasian: 11.7\%) and controls (Asian: 2.4\% vs. Caucasian: 11.1\%). A higher frequency of haplotypes 10-15 and 10-16 was observed in Asian patients compared to Caucasians patients but these differences were not significant. The CRHRA2 locus alleles, and haplotypes based on both loci did not show any association in both populations.

\section{Sib- transmission disequilibrium test}

A total of 43 South Asian and 64 Caucasian families with at least one affected and one unaffected sibling were included in the analysis. In the South Asian cohort, CRHRA1*10 was observed 18 times in RA-affected siblings compared to an expected value of 14.3 $(\mathrm{P}=0.10)$. However, there was no increase in the frequency of the ${ }^{*} 10$ allele in Caucasian affected siblings (19 observed compared with 18 expected). There was no excess in the frequency of CRHRA $2 * 14$ in affected siblings in both Caucasian and Asian groups, although CRHRA2*15 was under-represented in
Caucasian affected ( 4 observed vs. 10 expected, $\mathrm{P}=0.039$ ).

Only CRHRA2 showed a significant association with self reported severity by analogue scale $\left(\chi^{2}=156.4, \mathrm{df}=114, \mathrm{P}<0.01\right)$ of the disease in South Asians. The perception of pain assessed by analogue score followed a similar pattern to severity of RA.

\section{Discussion}

In the present study, a non-significant association was observed with CRHRA1* 10 in both populations (Caucasian OR $=1.32$, CI 0.772.28, South Asians, OR=1.55, CI 0.95-2.63).

The transmission disequilibrium test (SibTDT) analysis, although limited by small numbers, also showed evidence of preferential transmission of CRHRA1* 10 to South Asian RA cases. Although none of these findings result in a significant association, it is important to note that the sample sizes here are small, resulting in low power to detect a significant association. Nevertheless, the consistent trend towards an association with *10 allele in both case-control and sib-TDT studies suggests that further research with a larger sample of South Asians is warranted in order to clarify whether there is an association with RA. Based on the observed frequency of CRHRA1*10 in South Asians, approximately 600 case/control pairs would be required in order to achieve $80 \%$ power $(\alpha=0.05)$ to detect a significant association. There was no association with CRHRA2*14 in either population, although a second allele, CRHRA2*11, occurred at higher frequency in South Asian RA cases compared to controls $\mathrm{P}=0.005)$. The risk haplotype (CRHRA1*10-CRHRA2*14) reported in the previous UK study did not show any significant association in this study, consistent with the lack of a haplotype association observed in a Spanish cohort. ${ }^{13}$ In a genome-wide association study of microsatellite markers the $\mathrm{CRH}$ gene region was not associated with RA. ${ }^{16}$

It may be worth exploring these loci in future research as there is some evidence that stress may contribute to the RA pathology. ${ }^{17,18}$ Corticotropin-releasing hormone encoded by the $C R H$ gene, is a key integrator of stress responses, and, as such, $C R H$ gene variation may contribute to individual differences in susceptibility to stress-related pathology. ${ }^{19}$ $\mathrm{CRH}$ is the strongest known activator of the HPA axis, which has been functionally implicated in the regulation of many endocrine functions such as glucocorticoid release from the adrenal gland and associated endocrineimmune responses. ${ }^{19}$ Stress due to relationship difficulties, bereavement in the family or forced migration in South Asians may have had effect on the hypothalamic-pituitary-adrenal axis where either the polymorphisms in the CRH gene or their expression may have played a part in RA occurrence.

In a comparison of genotypes with the age, duration, severity and pain, only CRHRA2 showed a significant association with the severity in South Asian RAs. This observed association needs further comment. It may be due to the localised release of CRH leading to prostaglandin $\mathrm{E} 1$ and $\mathrm{E}_{2}$ release. This would culminate in inflammation and lowered pain threshold. ${ }^{7}$ The CRH levels detected in the synovial fluid from RA patients, although lower than in osteoarthritis, ${ }^{20}$ has the propensity to increase IL-6,18 from macrophages and increase its activity after combining with CRHbinding protein, ${ }^{21}$ and needs further research for its role in RA inflammation.

\section{References}

1. Del Rincon I, Battafarano DF, Arroyo RA, et al. Ethnic variation in the clinical manifestations of rheumatoid arthritis: role of HLA-DRB1 alleles. Arthritis Rheum 03;49: 200-8.

2. Plenge RM, Padyukov L, Remmers EF, et al. Replication of putative candidate-gene associations with rheumatoid arthritis in $>4,000$ samples from North America and Sweden: association of susceptibility with 
PTPN22, CTLA4, and PADI4. Am J Hum Gen 2005;77:1044-60.

3. Panayi GS. The pathogenesis of rheumatoid arthritis and the development of therapeutic strategies for the clinical investigation of biologics. Agents Actions Suppl 1995;47:1 21.

4. Cutolo M, Maestroni GJM, Otsa K, et al. Circadian melatonin and cortisol levels in rheumatoid arthritis patients in winter time: a north and south Europe comparison. Ann Rheum Dis 2005;64:212-6.

5. Crofford LJ, Sano H, Karalis K, et al. Corticotropin-releasing hormone in synovial fluids and tissues of patients with rheumatoid arthritis and osteoarthritis. J Immunol 1993;151:1587-96.

6. Robinson BG, Emanuel RL, Frim DM, Majzoub JA. Glucocorticoid stimulates expression of corticotropin-releasing hormone gene in human placenta. Proc Nat Acad Sci 1988;85:5244-8.

7. McEvoy AN, Bresnihan B, Fitzgerald 0, Murphy EP. Cyclooxygenase 2-derived prostagladin E2 production by corticotropin releasing hormone contributes to the activated cAMP response element binding protein content in rheumatoid arthritis synovial tissue. Arthritis Rheum 2004;50:1132-45.

8. Lin CR, Amaya F, Barrett L, et al. Prostaglandin E2 receptor EP4 contributes to inflammatory pain hypersensitivity. J Pharmacol Exp Ther 2006;319:1096-103.
9. Baerwald CGO, Mok CC, Tickly M ,et al. Corticotrophin releasing hormone (CRH) promoter polymorphisms in various ethnic groups of patients with rheumatoid arthritis. Z Rheumatol 2000;59:29-34.

10. Gonzalez-Gay MA, Hajeer AH, Garcia-Purro $\mathrm{C}$ et al. Corticotropin-releasing hormone promoter polymorphisms in patients with rheumatoid arthritis from northwest Spain. J Rheumatol 2003;30:913-7.

11. Fife M, Fisher SA, John S, et al. Multipoint linkage analysis of a candidate gene locus in rheumatoid arthritis: significant evidence of linkage and association with CRH genomic region. Arthritis Rheum 2000;43: 1673-8.

12. Fife $M$, Steer $S$, Fisher SA, et al. Association of familial sporadic rheumatoid arthritis with a single corticotropinreleasing hormone genomic region (8q12.3) haplotype. Arthritis Rheum 2002; 46:75-82.

13. Julià A, Gallardo D, Vidal F, et al. Association study between corticotrophinreleasing hormone genomic region (8q13) and rheumatoid arthritis in the Spanish population. Rheumatology 2003;42:1534-8.

14. Spielman RS, Ewens WJ. A Sibship test for linkage in the presence of association: the sib transmission/disequilibrium test. Am J Hum Genet 1998;62:450-8.

15. Xie X, Ott J. Testing linkage disequilibrium between a disease gene and marker loci. Am J Hum Genet 1993;53:1107.
16. Tamiya G, Shinya M, Imanishi $\mathrm{T}$ et al. Whole genome association study of rheumatoid arthritis using $27 \quad 039$ microsatellites. Hum Mol Genet 2005;14: 2305-21.

17. Geenen R, Godaert GL, Heijnen CJ, et al. Experimentally induced stress in rheumatoid arthritis of recent onset: effects on peripheral blood lymphocytes. Clin Exp Rheumatol 1998;16:553-9.

18. Straub RH, Kalden JR. Stress of different types increases the proinflammatory load in rheumatoid arthritis. Arthritis Res Ther 2009;11:114.

19. Malysheva O, Wagner U, Wahle M, et al. Hypothalamic-pituitary-adrenal axis stress test in patients with early RA: role of corticotropin-releasing hormone promoter polymorphisms. Ann Rheum Dis 2011;70: 2058-9.

20. Nishioka T, Kurokawa H, Takao T, et al. Differential changes of corticotropin releasing hormone (CRH) concentrations in plasma and synovial fluids of patients with rheumatoid arthritis (RA). Endocr J 1996;43:241-7.

21. Venihaki M, Dikkes P, Carrigan A, Karalis KP. Corticotropin-releasing hormone regulates IL-6 expression during inflammation. J Clin Invest 2001;108:1159-66. 